\title{
THE ROGUE TOMATO : A PROBLEM IN NUCLEAR, CYTO- PLASMIC AND ENVIRONMENTAL CONTROL
}

D. LEWIS

John Innes Horticultural Instituiion, Hertford

Received 26.iii.53

\section{INTRODUCTION}

THE tomato, Lycopersicon esculentum, in its native region, Peru, is crosspollinated to the extent of $5^{\circ}$ per cent. (Rick, 1950). In England the cultivated tomato is a greenhouse plant which has to rely entirely on self-pollination. The English varieties, therefore, are the result of selection for total self-fertilisation, and in consequence have been inbred for varying numbers of generations according to the age of the variety. When grown in the open ground English varieties do undergo some cross-pollination; the occasional practice of raising seed out-of-doors would mean that a small amount of crossing would have occurred at some time in the life of a variety. But in general the varieties are highly inbred and true-breeding.

There is, however, an off-type or rogue which has segregated for many generations in several varieties. This off-type has been given many names such as "Jack", "Feather Leg" and " Rogue". The latter term has come into general use and is adopted here. I shall use the term in a specific sense for the one type of plant to be described and not in the general sense of any segregating off-type which occurs in a cultivated crop. The rogue plant has occurred sometimes as a rare mutant but also in 15 per cent. of seedlings in several varieties, and a frequency of $5^{\circ}$ per cent. has been recorded.

In the U.S.A. tomatoes have been selected for cultivation in the open ground and have not attained the same degree of self-fertilisation as English varieties. It is remarkable that rogues have not been seen in the U.S.A. varieties.

Crane (1939) bred from normal and rogue plants of the variety Balch's Fillbasket, but he could find no consistent difference between the two in the proportion of rogues produced in the progeny. He also showed that the rogue condition was not transmitted by grafting. Darlington (1944) on the grounds of irregular segregation and similarity with the rogue pea (Bateson and Pellew, 1920) put forward a theory of cytoplasmic control.

One other feature of the rogue tomato was the great difference in numbers of rogues segregating from samples of the same seed sown at different times. This strong environmental effect supported Darlington's hypothesis. With this background and a stimulus from the findings of Sonneborn in Paramecium that the reproductive rate 
of kappa particles in the cytoplasm is dependent upon temperature, I took up the problem with a view to testing the effect of environment with particular emphasis on temperature. If the environmental factors could be found and controlled then the problem would be resolved into elucidating the genetic control of a frequent segregant in an inbred line.

\section{MATERIAL}

Ailsa Craig.-This is an old commercial variety which has regular bilocular fruits. The original seed was obtained from Sutton \& Sons in $194^{\circ}$ and has been maintained from greenhouse-grown plants. Before the present experiments started single plants had been self-pollinated for 2 generations and during the experiment for a further 6 generations.

Leafmould Resister.-This variety has been derived from crosses involving at least three varieties. Seed was obtained in 1940 and has been maintained from greenhouse-grown plants.

Recessive stock, $d$ p s o ry. This stock was obtained in 1930 and has been rigorously inbred for at least 20 generations.

Lycoperiscon pimpinellifolium (yellow fruited). The origin of this stock is obscure but it is known to have been inbred for at least 4 generations before its use in the present work.

I am indebted to Mr Crane for the original seed of Ailsa Craig, Leafmould Resister and the recessive stock $d p$ s or $y$.

\section{DESCRIPTION OF ROGUE PLANTS}

The earliest difference between the Rogue and a Normal plant can be seen from 16-22 days after sowing, according to the temperature. At this stage the cotyledons are fully expanded and the first true leaves can just be seen. The normal seedling has the first leaf much larger than the second leaf, the rogue has the two leaves of about equal size. The terminal segment of the first leaf of the normal is much larger than the other segments of the leaf; while in the rogue the segments of the first leaf are about equal in size. The leaves at this stage also have a different poise: those of the rogue appear flatter than those of the normal plant. Some of these differences can be seen in the photographs, plate I.

As the plants develop, other differences become manifest. The internodes of the rogue are much shorter, the leaves are smaller and with fewer segments. The first inflorescence frequently aborts, and side shoots develop much more freely in the rogue, $c f$. photographs, plate I.

The general effect, the short internodes, the smaller leaves and the development of side shoots, is characteristic of an unbalanced auxin system resulting in loss of apical dominance.

The rogue characters persist throughout the life of a plant. But Crane (I939) has reported a rogue plant of the variety, Best of All, which produced more normal growth during development. In the present experiments rogue plants have not been seen to change to 


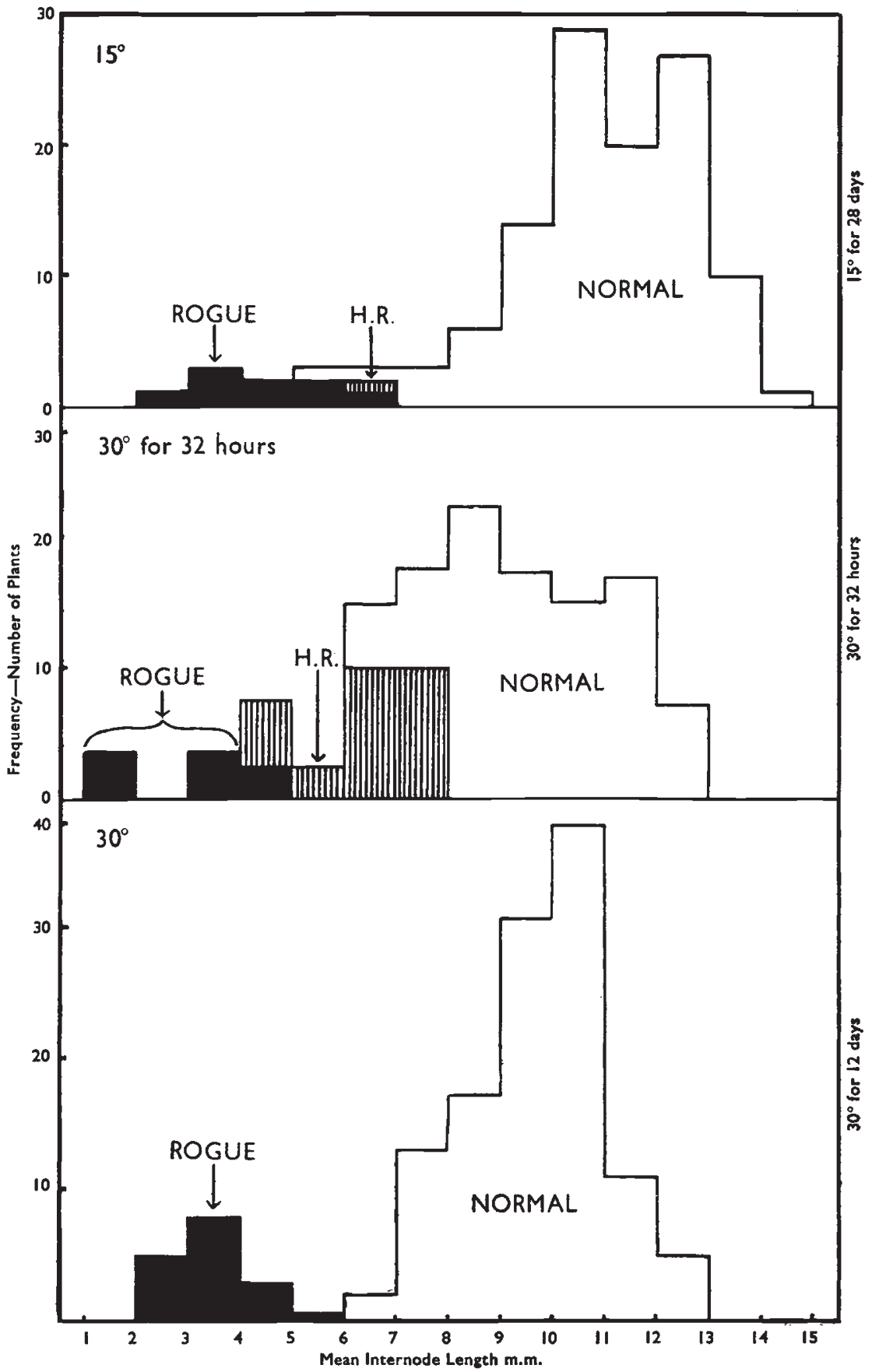

Fig. 1.-Mean internode lengths plotted against number of plants to show differences between the rogue, half-rogue and normal under three different germination treatments. The first 8 internodes were measured 45 days after cotyledon expansion : variety, Leafmould Resister. Note the high proportion of half-rogues at $30^{\circ}$ for 12 days. 
normal and, with one significant exception to be described later, normal plants have not been seen to change into rogues. There is, however, an intermediate type of plant described as a half-rogue. This type is intermediate in all its characters, and has occurred frequently under uncontrolled conditions.

Detailed measurements of all the rogue characters have not been made, since the results of measurements on internode lengths of normal, rogue and half-rogue plants give an adequate picture of the differences between the plants, and also of the range of variation found within the three types. Measurements were made on the length of the first 8 internodes; the mean internode length was calculated for each plant. The results are shown as histograms in text fig. I.

The internode length of the rogue is about a third that of the normal ; the half-rogue is intermediate. The $30^{\circ} \mathrm{C}$. treatment for $3^{2}$ hours induces a high percentage of half-rogues. They fall within the lower end of the normal distribution of the normal plants. This overlap does not cause any difficulty in distinguishing them. There are differences in leaf poise and leaf margins which are too subtle to describe but are, nevertheless, infallible guides. Their whole "syndrome" is characteristic of the rogue.

There is little overlapping of the true rogue and normal plants in internode lengths at $15^{\circ} \mathrm{C}$. and none at $30^{\circ} \mathrm{C}$.

TABLE I

The effect of temperature on the production of rogue plants from normal parents in the variety Ailsa Craig. The seedlings were kept at the controlled temperatures until the cotyledons had expanded. Tests of significance on the percentages of rogues transformed into angles (last column) show that all differences between treatments are significant except between 2 and 3. Each treatment was given to 2 boxes of roo seeds each. The plants received natural daylight through glass-sided incubators. For the purpose of temperature control the " day" period was fixed at 14 hours and the night period at ro hours. The seedlings remained in the controlled temperatures until the cotyledons had fully expanded. This was a period of 14 days at $26^{\circ}$, and 28 days at $12.5^{\circ}$.

\begin{tabular}{|c|c|c|c|c|c|c|}
\hline \multirow{2}{*}{ Treatment } & \multicolumn{2}{|c|}{ Temp. } & \multirow{2}{*}{$\begin{array}{l}\text { Germination } \\
\text { actual nos. }\end{array}$} & \multicolumn{2}{|c|}{ Rogues (per cent.) } & \multirow{2}{*}{$\phi$} \\
\hline & Day & Night & & on no. sown & on no. germ. & \\
\hline $\mathbf{I}$ & $26^{\circ}$ & $26^{\circ}$ & $\begin{array}{l}96 \\
97\end{array}$ & $\begin{array}{l}11 \cdot 0 \\
14 \cdot 0\end{array}$ & $\begin{array}{l}11 \cdot 4 \\
14.4\end{array}$ & $\begin{array}{l}\text { I } 9.8 \\
22.3\end{array}$ \\
\hline 2 & $26^{\circ}$ & $12 \cdot 5^{\circ}$ & $\begin{array}{l}89 \\
94\end{array}$ & $\begin{array}{l}6 \cdot 0 \\
8 \cdot 0\end{array}$ & $\begin{array}{l}6 \cdot 7 \\
8 \cdot 5\end{array}$ & $\begin{array}{l}14.9 \\
16 \cdot 9\end{array}$ \\
\hline 3 & $12 \cdot 5^{\circ}$ & $26^{\circ}$ & $\begin{array}{l}87 \\
86\end{array}$ & $\begin{array}{l}7 \cdot 0 \\
7 \cdot 0\end{array}$ & $\begin{array}{l}8 \cdot o \\
8 \cdot 0\end{array}$ & $\begin{array}{r}16.4 \\
16.4\end{array}$ \\
\hline 4 & $12 \cdot 5^{\circ}$ & $12 \cdot 5^{\circ}$ & $\begin{array}{l}91 \\
82\end{array}$ & $\begin{array}{l}0 \cdot 0 \\
3 \cdot 0\end{array}$ & $\begin{array}{l}0.0 \\
3.5\end{array}$ & $\begin{array}{r}0.0 \\
10.7\end{array}$ \\
\hline
\end{tabular}




\section{ENVIRONMENTAL CONTROL}

\section{(i) Means of transformation or re-orientation}

(a) On progeny from normal plants of high-rogue producing varieties.-The results of four heat treatments given during germination to the variety Ailsa Craig are given in table I.

Tests of significance show that all the comparisons are significant except $2: 3$. The high temperature treatment, I produces about eight times as many rogues as the low temperature treatment, 4 .

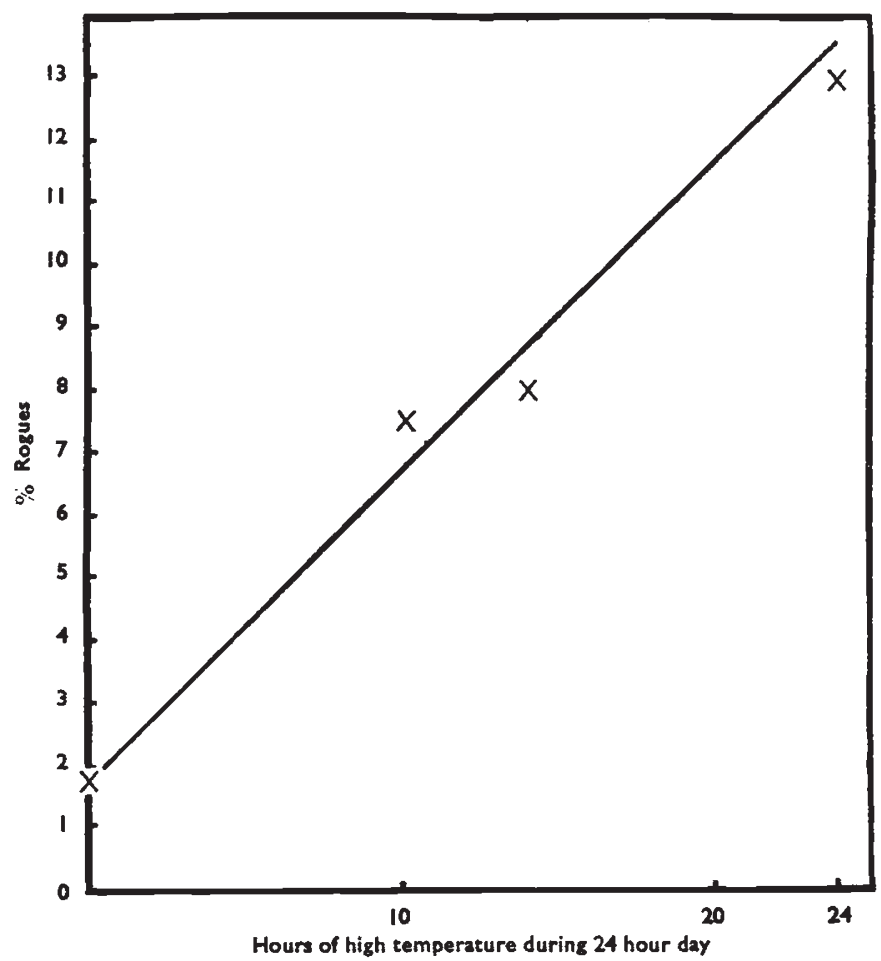

Fig. 2.--Percentage of rogues in Ailsa Craig pletted against the number of hours of heat treatment in each day : data extracted from table I. Note the linear proportionality between the percentage of rogues and the number of hours of heat treatment.

It is immaterial whether the heat treatment is given during the dark or light period. For the results show that there is a linear proportionality between the percentage of rogues and the number of hours of heat treatment, despite the fact that one of the treatments was given in the dark and another in the light, see fig. 2.

Heat treatment was given to another H.R.P.* variety, Leafmould Resister, and the results were 6.6 per cent. of rogues at $14^{\circ}$ and I4. I per cent. at $26^{\circ}$. The effect is similar to that with Ailsa Craig but not so marked, and for this reason the later work was concentrated on Ailsa Craig. 
(b) On progeny of rogue plants. Seeds from 3 rogue plants obtained from Ailsa Craig were germinated at $30^{\circ}$ and $14^{\circ}$. The results are given in table 2. The effect of high temperature on rogue production is similar to that obtained with seed from normal plants (table 1 ). The difference between the 3 rogue parents in their rogue production, and the fact that a rogue parent can give fewer rogues than a normal parent will be discussed after the genetic control has been described.

TABLE 2

Percentage germination (actual numbers) and percentage of rogue plants produced from rogue parents of the variety Ailsa Craig under high and low temperature

\begin{tabular}{|c|c|c|c|c|c|c|}
\hline \multirow{3}{*}{ Temp. } & \multicolumn{6}{|c|}{ Parents } \\
\hline & \multicolumn{2}{|c|}{$R_{1}$} & \multicolumn{2}{|c|}{$\mathbf{R}_{2}$} & \multicolumn{2}{|c|}{$\mathbf{R}_{3}$} \\
\hline & Germ. & $\mathbf{R}$ & Germ. & $\mathbf{R}$ & Germ. & $\mathbf{R}$ \\
\hline $30^{\circ}$ & $9 r$ & 4.4 & 80 & $6 \cdot 3$ & 75 & 14.6 \\
\hline $14^{\circ}$ & 84 & 0.0 & 85 & $0 \cdot 0$ & 74 & $1 \cdot 3$ \\
\hline
\end{tabular}

(c) Low-rogue-producing varieties. A similar experiment to that carried out with the H.R.P. varieties was carried out with Potentate, a variety which has given only 0.5 per cent. of rogues in the routine sowings over a period of many years and Stonor's Exhibition, which has given $O \cdot I$ per cent. rogues. Only one rogue was produced out of the 400 seeds of Potentate sown for the four treatments, thus showing that the proportion of rogues could not be increased in this variety by heat-treatment during germination. Stonor's Exhibition, another L.R.P., also yielded a negative result with heat treatment.

\section{(ii) Process of transformation}

(a) Germination and rogue production.-It is important to determine whether the higher production of rogues by the heat-treatment is due (i) to the transformation of a potentially normal seed into a rogue seed or (ii) to the " rogue seeds" needing a higher temperature for germination than the " normal seeds." The increased number of rogues at a high temperature would then be simply due to increased germination.

The results in table I do show a tendency for higher germination at higher temperatures but a regression coefficient calculated on the percentage of germination and the percentage of rogues was not found to be significant.

Table 2 shows quite inconsistent relationships between germination and rogue production. For example with Rogue No. 3 although the 
germination was 75 and 74 per cent. in high and low temperatures respectively the corresponding percentages of rogues was 14.6 and I.3. Furthermore with Rogue No. 2 a higher percentage of rogues was found with a lower germination, while with Rogue No. I the opposite relationship was found.

The simplest explanation is that the rogue seedlings produced by heat treatment are actually induced by the temperature, a conclusion which is emphasised by the next experiment.

(b) Temperature-sensitive period.--Temperature treatments in the first series of tests were extended to the time when the cotyledons were fully expanded. This was about 28 days at $12.5^{\circ}$ and 14 days at $26^{\circ}$. In one experiment in which two groups of seedlings had been given $12.5^{\circ}$ and $26^{\circ}$ respectively until cotyledon expansion, the groups were then sub-divided and each batch was again treated at two different temperatures. The second treatment had no effect : the first treatment alone determined the proportion of rogues produced, showing that, although the rogue condition is labile in the early stages of germination, it soon becomes absolutely stable.

An experiment was set-up to determine more precisely the sensitive period within the first labile stage of germination. Seeds of two H.R.P. varieties, Ailsa Graig and Leafmould Resister were sown at $14^{\circ}$ and given short periods ( 32 hours) at $30^{\circ}$ at 6 -day intervals from sowing. The results are given in fig. 3 .

In Ailsa Craig, the experiments reveal that the most sensitive period for true rogue induction is about 18 days after sowing at $14^{\circ}$. For at this period the 32-hour treatment transformed 6 per cent. of the seedlings into rogues; this is about half the transforming effect of high temperature given for the whole of the period from sowing to cotyledon expansion. The first heat treatment given at sowing time and the last treatment at 24 days after had no effect on rogue production.

The variety Leafmould Resister shows a similar trend to that of Ailsa Graig but the most sensitive period for true rogue production is 12 days after cotyledon expansion. The period also in Leafmould Resister seems to be less sharply differentiated because all the heat treatments raise the frequency of rogues.

But the most interesting and unexpected effect of the short treatments in both varieties is the induction of the intermediate plantsthe half-rogues, which have been described earlier. In the respect of half-rogue induction the two varieties show a similar pattern of response : half-rogues are produced by all short heat treatments and a maximum at the 18 -day treatment.

Half-rogues have appeared from time to time in normal routine sowings (Grane, I939). They are as stable as normal and rogue plants and do not revert as they get older to normals or rogues. They are a distinct class. Under normal greenhouse conditions of germination short periods of high temperature would be fairly common, and 
these would account for the occurrence of half-rogues. It is significant in this respect that no half-rogues are produced when the temperature

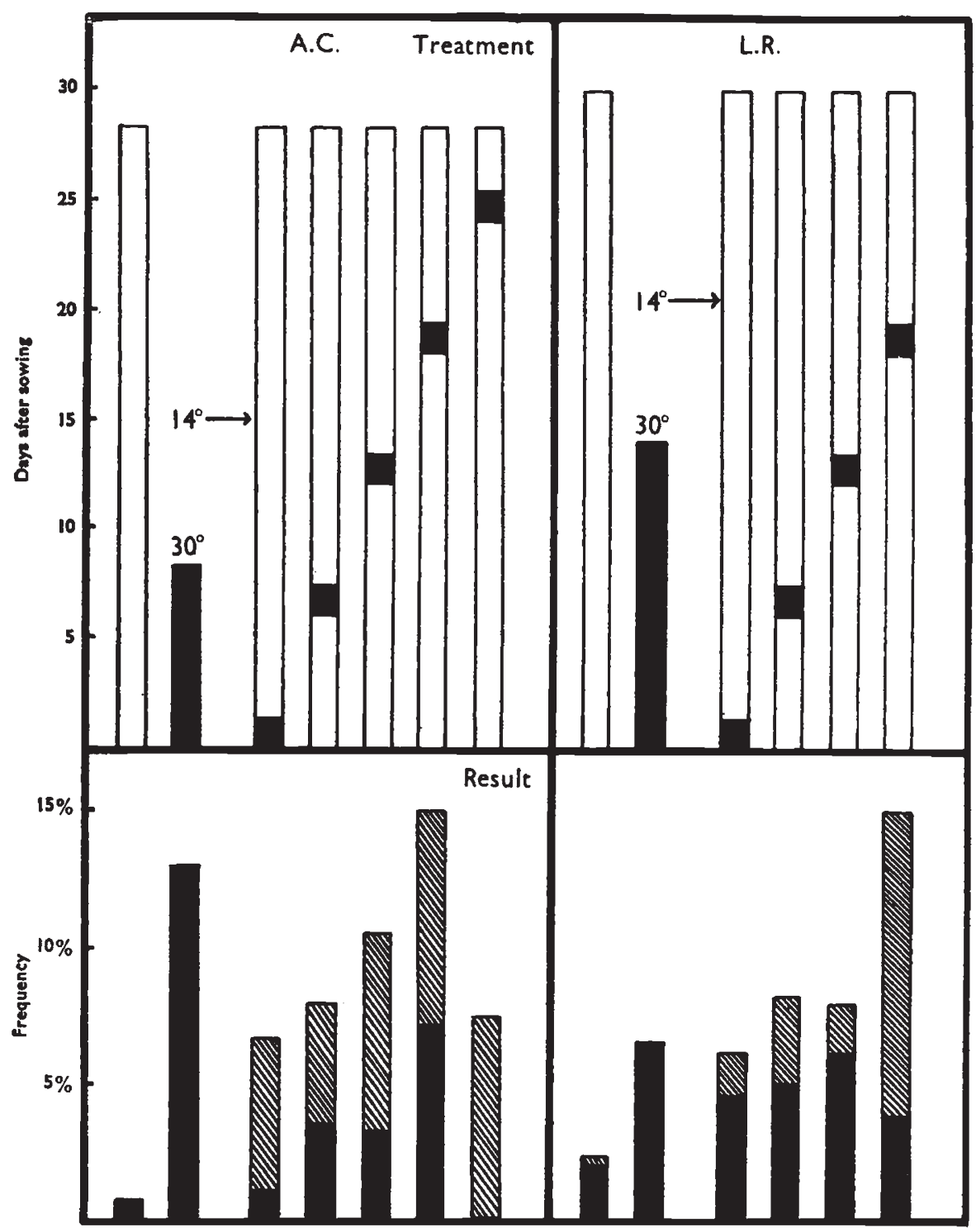

FIG. 3.-The results of experiments to determine the sensitive period during germination for the heat treatment effect. Above : heat treatments for 32 hours given at six-day intervals (indicated $\square$ ) are compared with heat treatments given for the whole of the germination period. Below : the frequency of rogues $\mathbf{v}$ and half-rogues Note the high proportion of half-rogues produced by the short heat treatments, and the most sensitive period at 20 days. A.C., Ailsa Craig : L.R., Leafmould Resister.

treatment, whether high or low, is given for the whole of the germination period. 
The fact that some of the short heat treatments, which increased the proportion of rogues, were given after germination, excludes the explanation of the temperature effect on a basis of differential germination of the rogue and normal. Furthermore the half-rogues produced only by the short heat treatments are desicive evidence for an actual transformation or re-orientation from normal to rogue.

(c) Day-length and light intensity at germination.-In the course of several years it had been noticed that fewer rogues were produced in summer than in winter sowings. As the temperature of sowing in a warm greenhouse would be of the same order in winter and in summer, other environmental differences had to be sought. Light intensity and duration, showing as they do a wide variation throughout the year, were obvious factors to investigate.

An experiment using the variety Ailsa Craig and a constant temperature of $30^{\circ}$ was designed to show the effect of light. The light was natural daylight in June, the seeds were sown on I I th June and the different treatments were continued until igth June. Thus the day-length would be almost at its maximum and the light intensity was high during this period. There were four treatments (table 3).

\section{TABLE 3}

Shows the effect of reducing the day-length and light intensity on rogue production. Seed of Ailsa Craig at $30^{\circ} \mathrm{C}$.

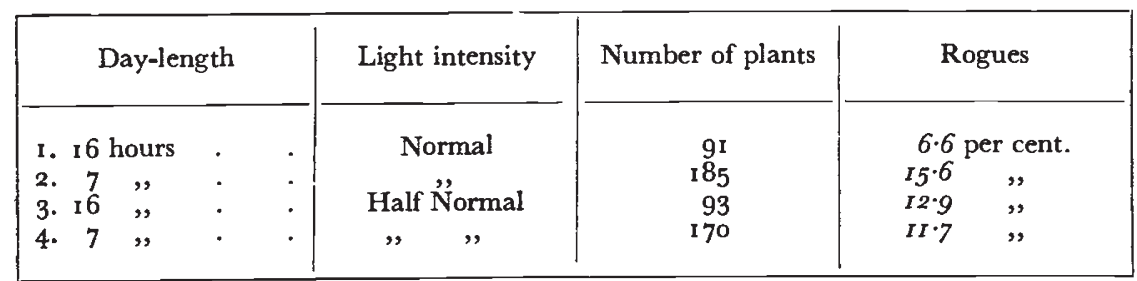

1. Control. Natural day-length (approx. 16 hours) and natural intensity.

2. Reduced day-length. A 7-hour day obtained by covering the seedlings.

3. Reduced intensity. Intensity reduced to half by covering with muslin, natural daylength.

4. Reduced intensity and reduced day-length. Combination of treatments 2 and 3 .

It will be seen that the control gives about half the percentage given by the same variety grown at the same temperature in the short days and low light intensity of February. Reducing the daylength and intensity separately have doubled the frequency of rogues to 12 or I 5 per cent., which is comparable with February results. The combination of reduced day-length and light intensity do no more.

\section{(iii) The developmental effect}

Selfed seeds collected from different inflorescences of a normal plant of Ailsa Craig were sown separately in two lots ; one lot of each 
at $30^{\circ} \mathrm{C}$. and the other at $14^{\circ}$. The number of rogues produced from the first four inflorescences are given in table 4 .

TABLE 4

Shows the effect of inflorescence on the production of rogues by normal plant of Ailsa Craig. Sown February 1948

\begin{tabular}{|c|c|c|c|c|}
\hline \multirow{2}{*}{ Inflorescence } & \multicolumn{2}{|c|}{$30^{\circ} \mathrm{C}$. } & \multicolumn{2}{|c|}{$14^{\circ} \mathrm{C}}$. \\
\hline & Germ.* & Rogues & Germ.* & Rogues \\
\hline $\begin{array}{l}1 \\
2 \\
3 \\
4\end{array}$ & $\begin{array}{l}94 \\
85 \\
95 \\
88\end{array}$ & $\begin{array}{l}15 \cdot 9 \text { per cent. } \\
14 \cdot 1 \quad ", \\
20 \cdot 0 \quad ", \\
25 \cdot 0 \quad "\end{array}$ & $\begin{array}{l}90 \\
92 \\
87 \\
91\end{array}$ & $\begin{array}{l}5.5 \text { per cent. } \\
3.6 \quad ", \\
\text { I } 1.4 \quad ", \\
9.0 \quad ",\end{array}$ \\
\hline
\end{tabular}

Analysis of variance on angles.

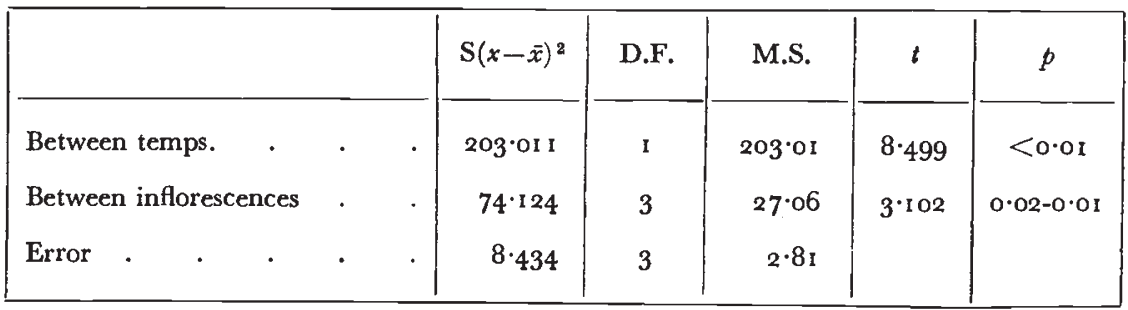

* Actual numbers out of roo seeds sown.

There is a trend from low-rogue-production by the ist and 2nd inflorescence to a higher production by the 3 rd and 4 th. An analysis of variance on the percentages transformed into angles shows that the differences between the inflorescences are on the verge of significance, $p=0 \cdot 02-0 \cdot 01$.

A further test was made using the seed from three different normal plants, and recording the rogues produced from the first five inflorescences. The seed was sown at $14^{\circ}$ in randomised positions in a glass incubator. The results of this test showed the same trend from low in the Ist and 2nd to high in the $3 \mathrm{rd}$ and $4^{\text {th }}$ with a drop in the $5^{\text {th. }}$

The analysis of variance for this test showed that the effect of inflorescence was not statistically significant and the error, which is composed mainly of inflorescence-plant interaction, is very high.

The high inflorescence-plant interaction was due to the position of the maximum which in some plants was at the $3^{\text {rd inflorescence }}$ and in others at the $4^{\text {th. }}$

Still a third test was made on seed from two other normal plants, and again the same trend was found.

Although none of the tests taken separately gave a significant effect for the inflorescences, taken together there can be little doubt of the genuine reality of the increase from ist and 2nd inflorescence to the $3^{\text {rd }}$ or $4^{\text {th }}$ according to the plant. 
Fig. 4 shows the combined results of the tests on plants which were scored for five inflorescences. If all the data from all tests are combined the mean figure for the ist and 2 nd inflorescence is 8.05 and for the $3^{\text {rd }}$ and 4 th, 13.42 .

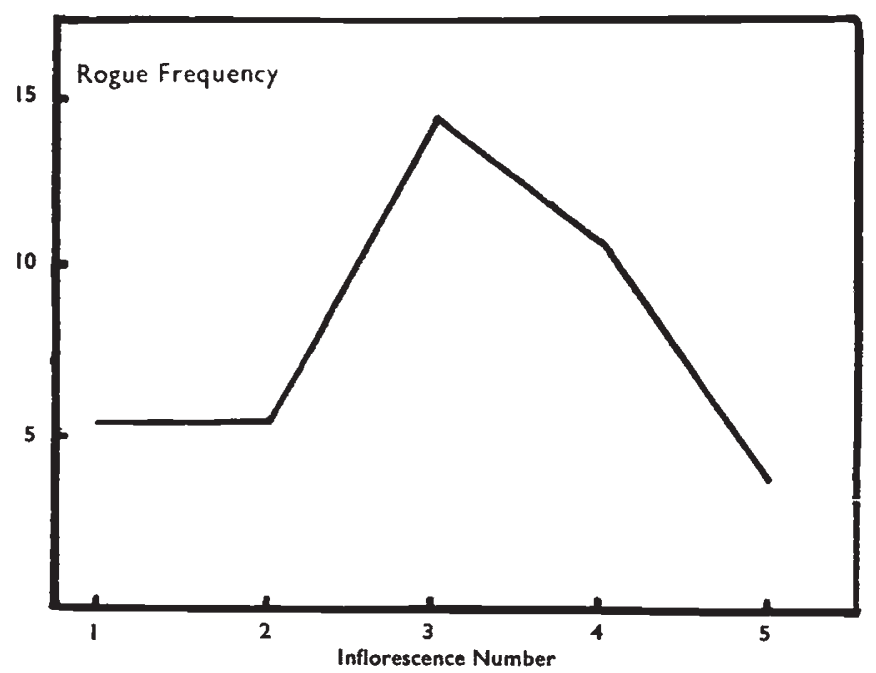

Fig. 4.-Percentage of rogues plotted against the inflorescence number from which the seed was obtained : variety Ailsa Craig : mean of all data from 4 different plants.

\section{GENETICAL CONTROL}

\section{(1) Breeding tests}

(a) Within a high-rogue-producing inbred line.-Normal and rogue plants selected at random from inbred material of the variety Ailsa Craig were self-pollinated. The seeds were collected from the first four inflorescences, and the seed that was sown was a mixture of equal numbers from the four inflorescences. This obviated any differences which could be due to the inflorescence (table 5).

TABLE 5

Percentage of rogues produced by different rogue and normal plants from an inbred line of Ailsa Craig, germination at $15^{\circ}, \mathrm{Feb} .195^{\circ}$

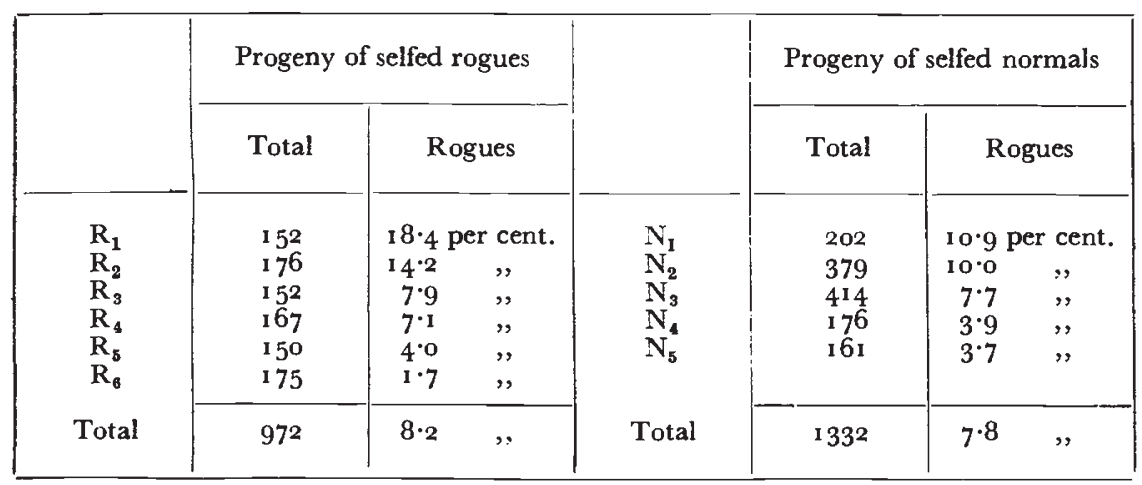


Taken together the percentage of rogues produced from rogue and normal plants is the same. There is, however, considerable variation between plants within both classes. The rogue parents appear to vary more than the normals in this respect. Because of this genetic similarity between rogues and normals no consistent difference would be expected between selfing and inter-crossing them. In the one pair of crosses that was made the results obtained are consistent with this view, as the following figures obtained at $30^{\circ}$ show :-

$$
\begin{array}{ll}
\mathrm{N}(\mathrm{I} 3 \cdot 2) \times \mathrm{R}(29 \cdot \mathrm{I}) & \mathrm{I} 8 \cdot 7 \text { per cent. } \mathrm{R} \\
\mathrm{R}(29 \cdot \mathrm{I}) \times \mathrm{N}(\mathrm{I} 3 \cdot 2) & \mathrm{I} \mathrm{I} \cdot 7 \text { per cent. } \mathrm{R}
\end{array}
$$

From these results it can be concluded (I) that the difference between the rogue and normal within Ailsa Craig is phenotypic and not genetic. At least, if the difference is genetic, passing through the sex cells has a levelling effect similar to the effect it has on virusinfected plants. (2) All individuals appear to have the potentiality to be either rogue or normal.

(b) Within a low-rogue producing variety.-The results within the L.R.P. variety, Stonor's Exhibition, are given in table 6. One rogue

TABLE 6

Progeny obtained from L.R.V., Stonor's Exhibition crosses, germinated at $30^{\circ} \mathrm{C}$.

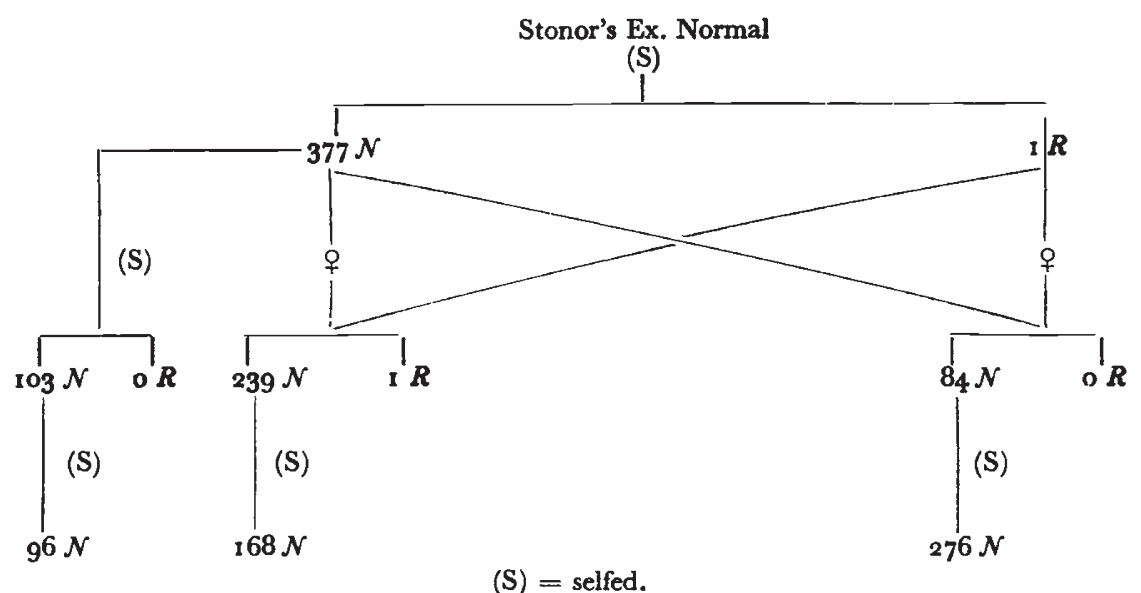

was obtained out of 378 plants which had germinated at $30^{\circ}$. This rogue would produce no seed on selfing : it was more sterile than the rogue in Ailsa Craig. On crossing reciprocally with the normal, one rogue was produced out of 323 plants; this was about the expected number from normal parents. Selfing for a further generation produced no rogues.

Thus in Stonor's Exhibition which produces about o.I per cent. of rogues the difference between rogue and normal, as in Ailsa Craig, 
is not inherited : it is phenotypic. The genetic control must thus be sought not within a line but between an H.R.P. and a R.F.* line.

Two hypotheses for these results can be formulated :-

(I) The pure line, Ailsa Craig, is homozygous for a gene or genes with a low penetrance which determine the rogue character. The penetrance being higher at a high temperature, during late development and under low light.

(2) The rogue is determined by competing cytoplasmic particles, the balance of which can be easily changed by the same conditions.

To discriminate between these two hypotheses a series of crosses were made between Ailsa Craig rogue and two different rogue-free lines.

(c) Within tetraploid rogue line.-A tetraploid strain of the variety Sunrise was produced by somatic doubling by $\mathrm{Mr} \mathrm{A}$. Gavin Brown, who very kindly made the following data available to me. The diploid Sunrise had given under uncontrolled conditions a mean of 5.4 per cent. rogues over a period of years and in the generation prior to chromosome doubling it gave I I 7 per cent.

The tetraploid normal plants produced 37 per cent. rogues and the tetraploid rogues produced 47 per cent. under uncontrolled conditions. The same tetraploid strain germinated at $30^{\circ}$ produced 74 per cent. rogues from normal plants.

(d) Between rogue-producing and rogue-free lines.-The H.R.P. variety was again Ailsa Craig ; two R.F. lines were used.

I. An inbred line carrying 6 recessive genes as follows :-

d for dwarf-habit

p for pubescent fruit

$s$ for compound inflorescence o for oval fruits $\mathbf{r}$ for colourless fruit flesh y for colourless fruit skin

2. An inbred line of Lycopersicon pimpinellifolium with yellow fruits. This specics is closely related to the tomato, and the cross, the $F_{1}$ and later generations are fully fertile.

Neither of these two lines have been known to give a single rogue plant.

Four $\mathrm{F}_{1}$ families were raised from the d p s o r y line ; Ailsa Craig Rogue $\times d p$ s o r $y$ and reciprocal and Ailsa Craig Normal $\times d p$ s o r $y$ and reciprocal. The total number of plants raised was 534, out of which no rogues were produced. The four $F_{2}$ families derived from the four $F_{1}$ 's totalled 860 plants, none of which was a rogue. All the families were germinated at $30^{\circ} \mathrm{C}$. in March. There were, however, three plants which had a slight resemblance to the rogue and were classified as half-rogues. There was some difficulty in scoring in 
the $F_{2}$ generation because of the effects of the many genes segregating, and it may be that the three plants were not half-rogues but contained certain combinations of genes which produce a phenotype resembling the rogue.

The results with $L$. pimpinellifolium in the $F_{1}$ and $F_{2}$ given in table 7 are similar to those obtained with the $d p s$ or $y$ line. The $\mathrm{F}_{3}$ takes the analysis a stage further. The results show that the rogue

TABLE 7

Results of $F_{1}, F_{2}, F_{3}, B_{1}$ and $B_{2}$ generations between Lycopersicon pimpinellifolium $(=P)$ and a rogue from Ailsa Craig $(=R)$. Germination at $30^{\circ} \mathrm{C} ., \frac{1}{2} R=$ half-rogue

\begin{tabular}{|c|c|c|c|c|c|c|c|c|}
\hline \multicolumn{9}{|c|}{ F Generations } \\
\hline \multicolumn{3}{|c|}{$\mathbf{P} \times \mathbf{R}$} & & & \multicolumn{4}{|c|}{$\mathbf{R} \times \mathbf{P}$} \\
\hline Total & $\frac{1}{2} R$ & $\mathbf{R}$ & & & Total & & $\mathbf{R}$ & $\mathbf{R}$ \\
\hline $\begin{array}{r}148 \\
400 \\
1120\end{array}$ & $\begin{array}{l}0 \\
0 \\
4\end{array}$ & $\begin{array}{l}0 \\
0 \\
0\end{array}$ & $\begin{array}{l}\mathbf{F}_{1} \\
\mathbf{F}_{2} \\
\mathbf{F}_{3} \\
\mathbf{F}_{3}\end{array}$ & & $\begin{array}{l}140 \\
338 \\
774 \\
173\end{array}$ & & $\begin{array}{l}0 \\
1 \\
0 \\
0\end{array}$ & $\begin{array}{c}0 \\
0 \\
0 \\
19\end{array}$ \\
\hline \multicolumn{9}{|c|}{ Backcross I (8 different crosses) } \\
\hline & & Total & \multicolumn{2}{|c|}{$\frac{1}{2} R$} & $\mathbf{R}$ & & & \\
\hline & & 1631 & \multicolumn{2}{|c|}{ I } & o & & & \\
\hline \multicolumn{9}{|c|}{ Backcross 2} \\
\hline & Total & $\frac{1}{2} R$ & $\mathbf{R}$ & Total & $\frac{1}{2} R$ & $\mathbf{R}$ & & \\
\hline $\begin{array}{c}\mathrm{F}_{1} \\
\mathrm{P} \times \mathrm{P} \times(\mathrm{R} \times \mathbf{P}) \\
\mathrm{P} \times \mathrm{P} \times(\mathbf{P} \times \mathbf{R}) \\
(\mathrm{R} \times \mathrm{P}) \times \mathbf{P} \times \mathbf{P} \\
(\mathrm{P} \times \mathrm{R}) \times \mathbf{P} \times \mathbf{P}\end{array}$ & $\begin{array}{l}150 \\
150 \\
150 \\
150\end{array}$ & $\begin{array}{l}0 \\
0 \\
\circ \\
0\end{array}$ & $\begin{array}{l}\circ \\
\circ \\
\circ \\
0\end{array}$ & $\begin{array}{l}150 \\
150 \\
150 \\
150\end{array}$ & $\begin{array}{l}0 \\
0 \\
0 \\
0\end{array}$ & $\begin{array}{r}10 \\
6 \\
32 \\
41\end{array}$ & & $\begin{array}{l}\times \mathbf{R} \times \mathbf{R} \\
\times \mathbf{R} \times \mathbf{R} \\
(\mathbf{R} \times \mathbf{P}) \\
(\mathbf{P} \times \mathbf{R})\end{array}$ \\
\hline
\end{tabular}

is suppressed in the $F_{1}$ and $F_{2}$ except for one plant in the $F_{2}$ which was a half-rogue. This represents $0^{\prime} I_{3}$ per cent. of the $F_{2}$ generation. The $F_{3}$ from this plant gave about Io per cent. of true rogues. The $\mathrm{F}_{3}$ from normal $\mathrm{F}_{2}$ plants contained no true rogues but segregated 0.63 per cent. of half-rogues. Thus we have to conclude that genes or cytoplasm or both from the rogue-free line completely suppress the rogue. 
The backcross data given in the same table (7) are more instructive than the $F$ generations. The first generation backcross made to either parent by either of the reciprocal $F_{1}$ 's produces no true rogues. This again is similar to the $F_{2}$ generation; and the 0.12 per cent. of half-rogues in the backcross is of the same order as the 0.13 per cent. produced in the $\mathrm{F}_{2}$ generation. The second generation backcross shows a remarkable change. Backcrossing the $F_{1}$ twice to the R.F. parent whether as $\delta$ or $q$, as expected from the $\mathrm{F}_{2}$ and ist backcross results, produces no rogues or half-rogues. Backcrossing twice to the rogue-producing parent, however, gives a high percentage of full rogues. Furthermore there is a significant difference between these backcross families according to whether the rogue is the recurrent female or male parent. The way in which the original cross was made in producing the $F_{1}$ generation has no effect on the number of rogues produced in the $\mathrm{B}_{2}$ generation. The following $2 \times 2$ table illustrates these differences.

TABLE 8

Numbers of rogues in $B_{2}$ families of 150 plants each, arranged in a $2 \times 2$ table to show the effect of the sex of the recurrent $R$ parent and the lack of effect of the direction in which the original cross was made.

\begin{tabular}{|c|c|c|c|c|}
\hline $\begin{array}{l}\text { Recurrent } \\
\text { R parent }\end{array}$ & $\mathrm{F}_{1}$ & $(\mathrm{R} \times \mathrm{P})$ & $(\mathbf{P} \times \mathbf{R})$ & Total \\
\hline $\mathbf{R}$ o & . & 10 & 6 & 16 \\
\hline $\mathbf{R} q$. & . & 32 & $4^{I}$ & 73 \\
\hline Total & . & $4^{2}$ & 47 & \\
\hline
\end{tabular}

Thus 4.5 times as many rogues are produced when the recurrent female parent is the H.R.P. line as when the $F_{1}$ hybrid and $B_{1}$ are the female parents.

The rogues which appear in the $B_{2}$ generations were new in one important respect. The rogues in Ailsa Craig can be detected with almost 100 per cent. certainty in the cotyledon stage some $16-22$ days after sowing, but the rogues in the $B_{2}$ generations could not be detected until much later. No rogues could be detected on the $5^{6 \text { th }}$ day after sowing and only 4 plants could be classified as halfrogues. On the 66 th day rogues could be detected and the number increased to a maximum on the 79th day. Fig. 5 shows this increase in number of rogues recorded at different times after sowing.

The plants finally classified as rogues had, at that time, the full rogue appearance, they were not in any respect half-rogues, despite the late appearance of the rogue characters. They may be called late-rogues. 
(e) Selection for rogue and normal within a pure line.-The material used was Ailsa Craig, selections were made by picking out normal plants for the normal selection line and rogue plants for the rogue

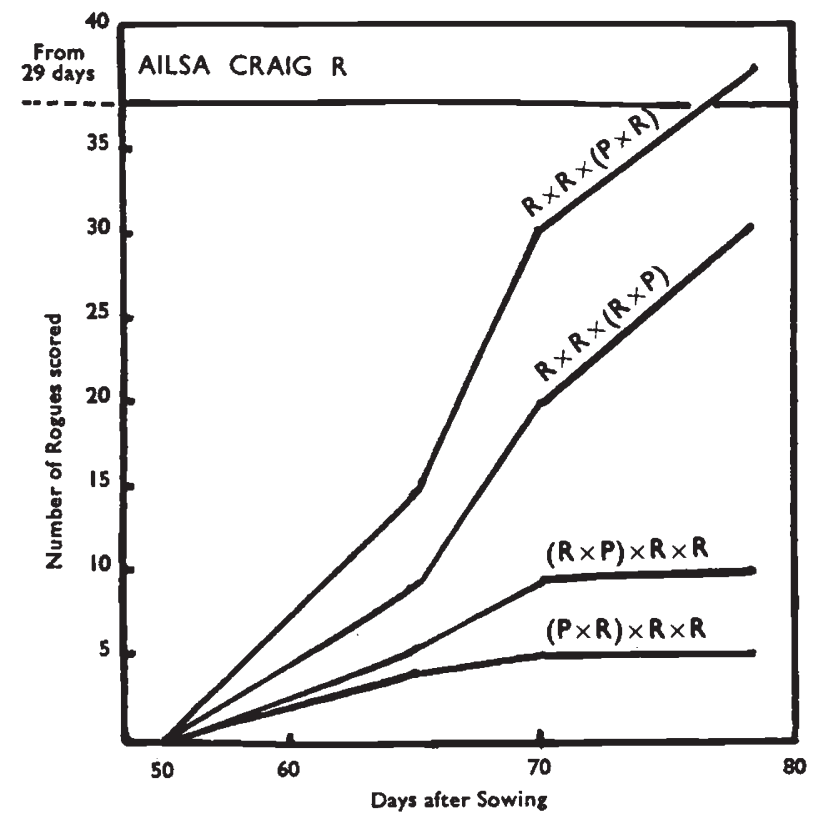

FIG. 5.-Number of rogues produced in the R-line of Ailsa Craig and 4 different $B_{2}$ generations of the R-line with $\mathrm{R}$-free line plotted against the number of days after sowing. Note the late development of the $\mathrm{R}$ character in the backcrosses as compared with the R-line of Ailsa Craig.

selection line. Two temperatures were used $25-30^{\circ}$ and $13^{\circ}$. There were therefore four main selection lines as follows :-

\begin{tabular}{ccc} 
Temperature & \multicolumn{2}{c}{ Selection } \\
$25^{\circ}-30^{\circ}$ & Normal & Rogue \\
$13^{\circ}$ & Normal & Rogue
\end{tabular}

Some of these main lines were split into a series of lines each originating from a different plant. The results of selection are shown in fig. 6 . Although the selections were done under different temperatures the rogue assay of each line was done at $30^{\circ}$. Selecting for normal plants was not effective at the high temperature and in fact the percentage of rogues produced increased slightly over three generations of selection. Normal selections at a low temperature showed a slight but nonsignificant response in the normal direction.

Selection for rogues results in an extremely erratic behaviour from generation to generation with no progress towards increasing the number of rogues. 


\section{(ii) Conclusions}

I. Within an H.R.P. inbred line, rogue and normal plants cannot be differentiated by their breeding behaviour. All plants appear to be potentially rogue.

2. Crossing reciprocally an H.R.P. line with a R.F. line causes suppression of the rogue potentiality in the $F_{1}, F_{2}, F_{3}$ and $B_{1}$. A slight rogue potentiality, as shown by 0.12 per cent. of half-rogues, is manifest in the $F_{2}$ and $B_{1}$.

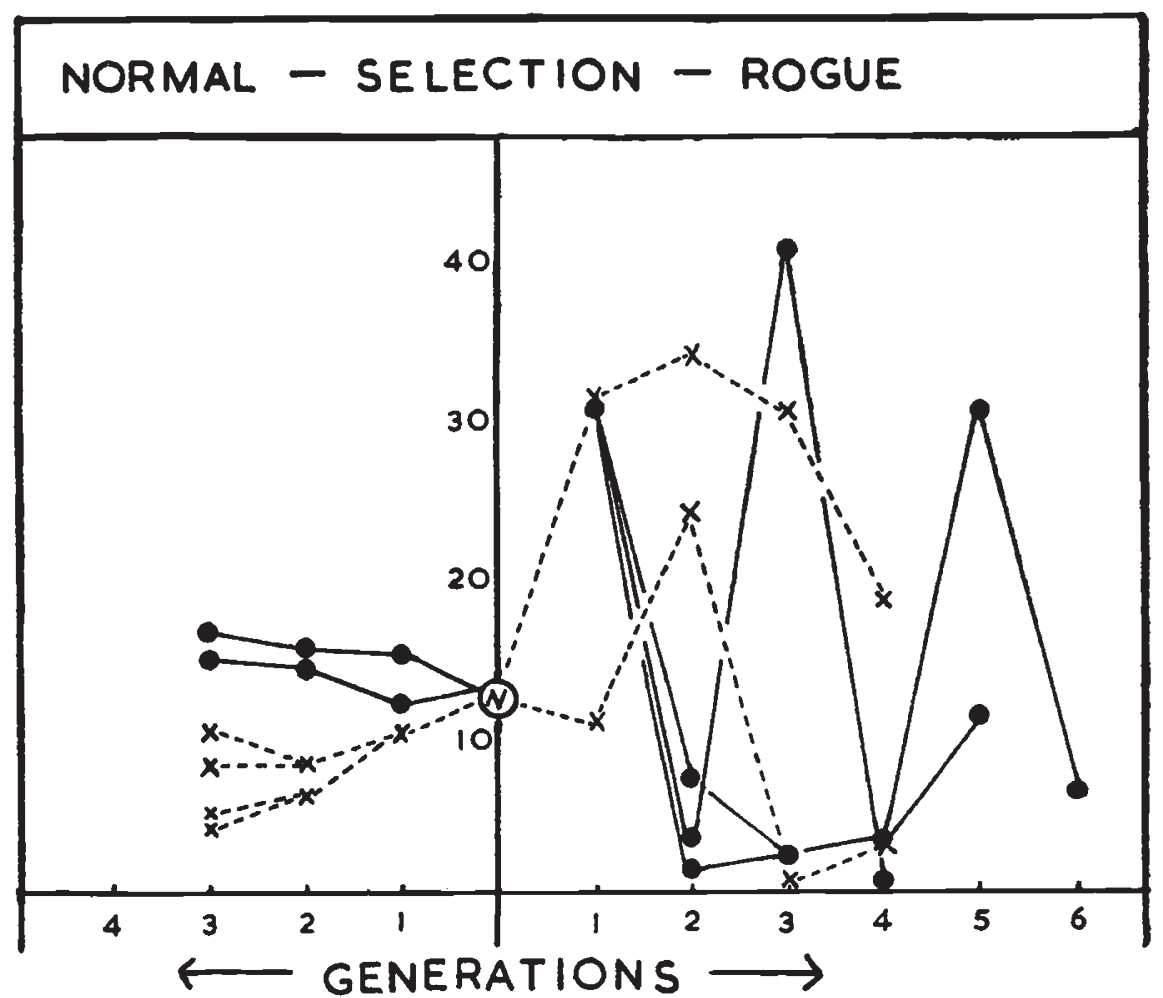

Fig. 6.-The results of selection for rogues and normals under high $\left(30^{\circ}\right)$ and low $\left(12 \cdot 5^{\circ}\right)$ temperatures. The tests were all made at $30^{\circ}$ : variety Ailsa Craig. ___ $30^{\circ}$ selection : - - $-\cdots \cdots,-\cdots, 5^{\circ}$ selection. The ordinate represents the percentage of rogues.

The $B_{2}$ generation using the R.P. line as the recurrent parent produces true rogues; and four times as many when the H.R.P. line is female as when it is the male.

3. The rogue plants in the $B_{2}$ generation, unlike those from an H.R.P. line, begin as normal seedlings and develop the rogue character later.

4. Selection for normals within an inbred line is not effective except at a low temperature and even then the response is small and of doubtful significance. 


\section{ALTERNATIVE HYPOTHESES}

(i) One or more genes with low penetrance determine the rogue potentiality of the $R$ line

This would fit the results obtained within the pure $R$ line in that all plants would be homozygous for the $r r$ genes and the phenotypic difference between normal plants and rogues in the line would be due to the difference in penetrance in the different plants.

Would this genic explanation fit the data from intercrossing an H.R.P. line and a R.F. line? The complete lack of rogues in $F_{1}$ could be explained by dominance of normal over rogue; complete absence in $\mathbf{F}_{2}$ could be explained on the assumption that there were about 8 different genes all of which must be homozygous recessive for rogue production.

The critical data of the backcrosses are given in table 9 together with the expected proportion of rogues on different numbers of genes

\section{TABLE 9}

Observed results from $B_{1}$ and $B_{2}$ of $R$ line crossed with $R$-free line compared with the expectations on a genic basis

\begin{tabular}{|c|c|c|c|c|c|c|c|c|c|c|}
\hline \multirow{2}{*}{$\begin{array}{l}\text { Numbers } \\
\quad \text { Total }\end{array}$} & \multirow{2}{*}{$\begin{array}{c}\text { R. Pheno- } \\
\text { types }\end{array}$} & \multirow{2}{*}{$\begin{array}{c}\text { R. Geno- } \\
\text { types }\end{array}$} & \multicolumn{8}{|c|}{ Expected on-Genes } \\
\hline & & & 2 & 3 & 4 & 5 & 6 & 7 & 8 & 9 \\
\hline $\mathrm{B}_{1} \quad \mathrm{I}^{*} \quad 3262$ & $\frac{1}{3^{262}}$ & $\frac{1}{65^{2 \cdot 4}}$ & $\frac{I}{4}$ & $\frac{1}{8}$ & $\frac{\mathrm{I}}{\mathrm{I} 6}$ & $\frac{1}{3^{2}}$ & $\frac{\mathrm{I}}{64}$ & $\frac{I}{128}$ & $\frac{1}{256}$ & $\frac{1}{5^{12}}$ \\
\hline $\mathrm{B}_{2} \quad 89 \quad 600$ & $\frac{1}{6 \cdot 74}$ & $\frac{I}{I \cdot 34^{8}}$ & $\frac{1}{2}$ & $\frac{\mathrm{I}}{4}$ & $\frac{1}{8}$ & $\frac{\mathrm{r}}{\mathrm{i} 6}$ & $\frac{1}{32}$ & $\frac{1}{64}$ & $\frac{1}{128}$ & $\frac{1}{256}$ \\
\hline
\end{tabular}

* The actual figures were $\mathrm{I}$ half-rogues in $\mathrm{r} 63^{\mathrm{I}}$ plants.

and assuming 20 per cent. penetrance of the bottom recessive. Thus to explain the $B_{1}$ generation 9 genes are necessary and to explain the $B_{2}$ generation more than 2 genes would give a significantly different result from the one observed.

Secondly the $B_{2}$ results were obtained from 4 different $B_{2}$ plants and no difference in results in the $B_{2}$ could be attributable to differences between the $B_{1}$ plants within a family, which must occur on a genic explanation. This fact, together with the large number of genes invoked in $B_{1}$ precludes a possible explanation of the $B_{2}$ results on an inadequate sample of the $B_{1}$.

Thirdly on the evidence from temperature effects, selection results, and reciprocal backcross differences, a purely genic hypothesis must be excluded. 
(ii) The difference between rogues, half-rogues and normals within an H.R.P line is due to a re-orientation of an unstable equilibrium in the somatic tissue during differentiation and development.

(a) This re-orientation does not affect the germ cells.

(b) Temperature, light and genotype influence the re-orientation of the unstable equilibrium.

(c) The direct control of the rogue-normal re-orientation is by a cytoplasmic factor which is transmitted more efficiently by the eggs than by the pollen.

\section{How does this scheme fit the facts?}

The difference between rogues and normals within an inbred H.R.P. line has been shown to be phenotypic and is not inherited. Selection for rogues and normals is ineffective. The effect of environ-
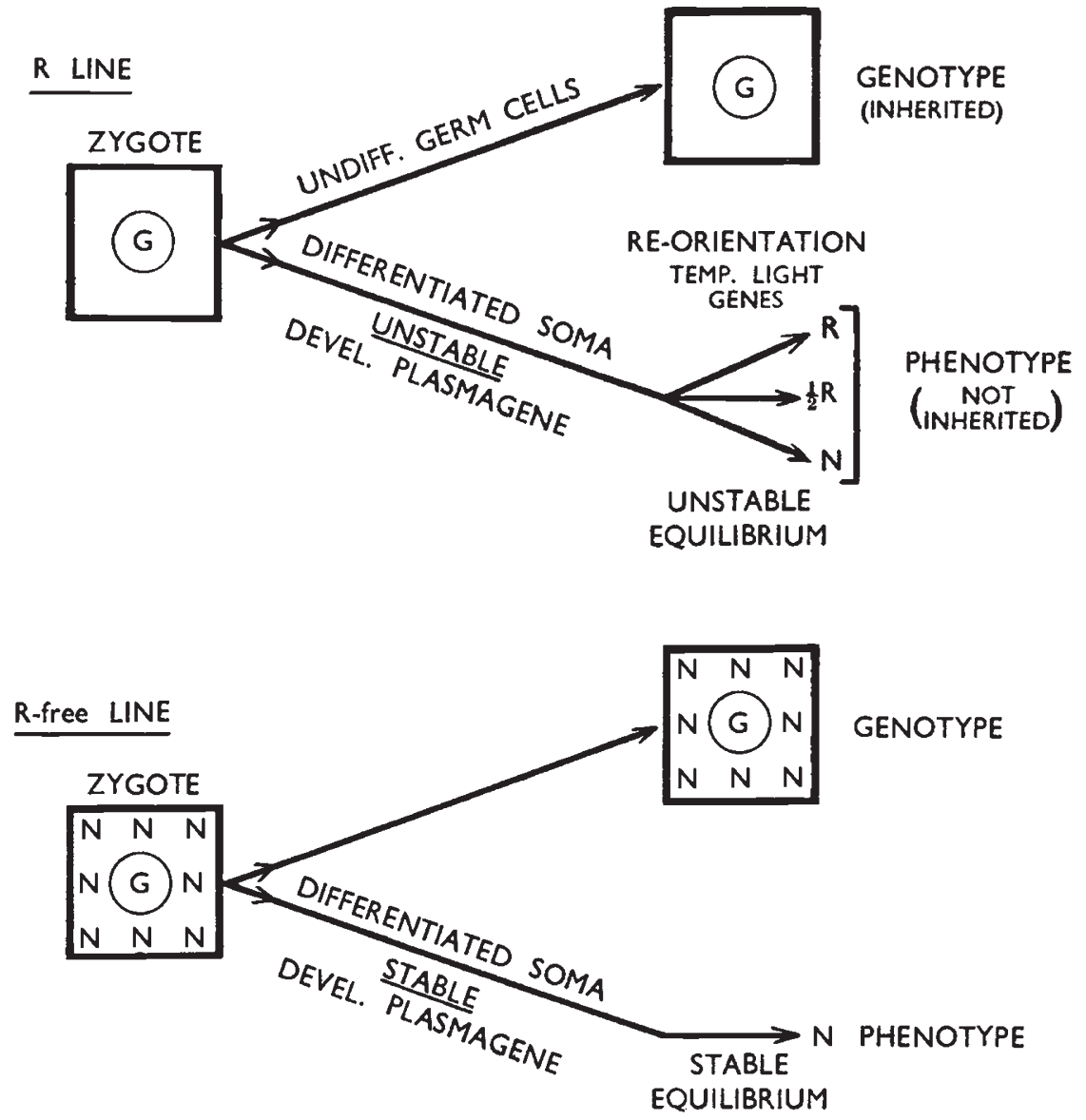

FIG. 7 .

ment is well defined : it re-orientates a seed along one of three paths, normal, half-rogue and rogue. This aspect of the problem is clear and accords with the hypothesis. 
The genetical control of the unstable equilibrium, which allows re-orientation to occur, has not been fully clarified. A purely genic basis on any number of genes with or without modification is incompatible with the data. The alternative to a direct genic control is a cytoplasmic determinant. But the difficulty in assessing a cytoplasmic factor in the present problem is the lack of big reciprocal differences in transmission. There are, however, reciprocal differences in the $B_{2}$ generations which show that the genetical determinants of the normal (stable equilibrium) are transmitted four times more efficiently through the eggs than through the pollen. On the other hand there are no reciprocal differences which can be attributed to the $F_{1}, F_{2}$ and $B_{1}$ generations. To reconcile these differences an added complication must be introduced : the reciprocal difference in transmission only operates when the number of determinants falls below a certain threshold value.

The differences in transnission between different inflorescences is to be expected with a cytoplasmic determinant, and despite the great difficulty with the present problem of separating genes and cytoplasm the cytoplasmic hypothesis is the only plausible one.

The tentative scheme is illustrated in fig. 7 .

\section{DISCUSSION}

In the past the idea had become firmly established that the main criterion for a cytoplasmic determinant in a higher plant was its maternal inheritance. Without this, other evidence was of no value. Recently, Darlington (1949) pointed out, however, that the best examples of cytoplasmic determinants - the chloroplasts-in the classical work of Baur and Chittenden were biparentally inherited. $\mathrm{He}$ also drew the important conclusion from the work of Bateson and Pellew (1920) not only that the rogue-pea was due to a cytoplasmic difference but that the rogue plasmagenes were transmitted more frequently through the pollen than through the egg. Biparental transmission of a plasmagene has been explained by Darlington in two ways :-

(I) that when the plasmagene reproduction is faster than cell reproduction then the plasmagene will accumulate most in the slowest growing cell of the plants-the pollen grain.

(2) That if the abnormal plasmagene suppresses the normal then the one or two plasmagenes which come through the pollen will eventually suppress the large number of normal plasmagenes in the egg.

If we turn to microorganisms maternal inheritance has not been the stumbling block to the interpretation of cytoplasmic inheritance that it has been in the flowering plants, because generally the two fusing cells are of equal size. In yeast, Ephrussi et. al (1949) and Chen, 
Ephrussi and Hottinguer (1950) have interpreted their results with the "petite" type which arises spontaneously and after acriflavine treatment during vegetative budding, on a cytoplasmic factor. Their data on a mendelian interpretation would require 6-20 nuclear genes. The present results on the rogue tomato do not show marked reciprocal differences except in certain families. The results cannot be explained on Mendelian lines however many genes are invoked as we saw.

The rogue tomato is similar in many respects to the rogue pea and the bolter potato. It differs, however, from the rogue pea in that the rogue is suppressive to normal in the pea while in the tomato the reverse is true-the normal suppresses the rogue. The bolter potato (Stanton, 1952) which is an abnormal type arising vegetatively, bears the greatest resemblance to the rogue tomato in that "the frequency of bolting in the progeny depends more on the variety than on the state, bolter or normal of the parents." The bolternormal difference within a variety of potato, as the rogue tomato, is phenotypic and not genetic. The rogue-normal difference in peas, on the other hand is genetic as well as phenotypic.

The complexity of systems of competing cytoplasmic determinants is evident from all work on cytoplasmic inheritance. This is very clearly shown by the work of Beale (1952) with the antigenic types in Paramecium where the system lends itself to a precise analysis of the interaction of genes, cytoplasm, and environment.

The induction of a stable and distinct class, the halt-rogues by short heat treatments is evidence that different equilibria between the competing plasmagenes can be attained in the cells. This would appear to be a general feature, for intermediate and transforming types are also found in the rogue pea and the bolter potato. The half-rogues also appear to have their counterpart in the " resistant non-killers" in Paramecium which are intermediate between "killer" and "sensitive", Sonneborn (1946). These were produced by short heat treatments as were the half-rogues in tomatoes; they differ, however, in that the "resistant non-killers" change to "killers" while the half rogues are stable.

The effect of temperature during germination on the rogue is very similar to that found by Sonneborn for the killer and by Beale (loc. cit.) for antigens in Paramecium; to the effect on $\mathrm{CO}_{2}$ sensitivity in Drosophila melanogaster (l'Héritier, 1948) ; and on the "Sex ratio" phenomenon in Drosophila bifasciata, Magni (1952).

The origin of the rogue tomato is obscure ; it may arise by mutation. Evidence from commercial growers points to this possibility. For example, the variety Stonor's Exhibition which has given only $0 \cdot 1$ per cent. of rogues at the John Innes Horticultural Institution has been known to produce in some commercial stocks as much as 30 per cent. of rogues. 
The problems which require solving are : the origin of the plasmagene differences, the precise nature of the competition between plasmagenes, and the nature of the intermediate types. The solution to these problems may have to be sought in more favourable material -material in which the actual plasmagenes and their differences can be seen in the cell.

Acknowledgments.-I wish to thank Prof. G. D. Darlington for valuable help in discussing the problem during the course of the work ; Miss V. P. J. Clarke for making many of the crosses and Miss L. K. Crowe for the diagrams.

\section{SUMMARY}

I. In several pure lines of tomatoes an abnormal but stable growth type of plant-rogue-occurs in proportions ranging from $0 \cdot I$ to 20 per cent. according to the line.

2. Four factors increase the frequency of rogues. (I) A high temperature during germination increases the frequency of rogues from $I \cdot 4$ per cent. at $13^{\circ}$ to 13 per cent. at $25^{\circ}-30^{\circ}$. This is due to a transformation or re-orientation in the seed. Intermediate typeshalf-rogues are produced by short heat treatments. (2) Low light intensity and short days during germination. (3) The position on the plant of the inflorescence from which the seed is obtained. The Ist and 2nd inflorescences give a lower percentage of rogues than the $3^{\text {rd }}$ and 4 th. (4) The genetic constitution.

3. Rogues and normals within a pure line behave similarly on selfing: both give approximately the same percentage of rogues, although rogues vary more. The difference between rogue and normal therefore is phenotypic and not genetic.

4. Crossing a rogue onto a rogue-free line results in suppression of the rogue in the $F_{1}, F_{2}, F_{3}$ and $B_{1}$ generations. The $B_{2}$ generation to the $\mathrm{R}$ line has its rogue potentiality restored. Reciprocal differences in transmission were only found in the $B_{2}$, where the female was four times as efficient in " normal " transmission as the male.

5. The results are inexplicable on any nuclear genic hypothesis because non-segregation in the $B_{1}$ demands at least 9 genes while segregation in the $\mathrm{B}_{2}$ does not allow of more than 2 genes.

6. A hypothesis based upon a "normal" plasmagene in the $\mathrm{R}$-free line and its absence in the $\mathrm{R}$ line is discussed.

\section{REFERENCES}

BAteson, W., AND PELlew, c. I920. The genetics of "rogues" among culinary peas (Pisum sativum). P.R.S., B, 9 I, I 86-I 95 .

BEALE, G. H. I952. Antigen variation in Paramecium aurelia, variety I. Genetics, $37,66-74$.

CHEN, S., EPHRUSSI, B., AND HOTTINGUER, H. I950. Nature genetique des mutants a deficience respiratoire de la souche B-i I de la levure de boulangerie. Heredity, $4,337-351$. 
Plate

Fig. 1. - Normal seedling (top), and rogue (below), 16 days after sowing at $26^{\circ} . \times 2$. Note the two true leaves in the rogue are of nearly equal development, while in the normal the first leaf is more advanced than the second.

Fig. 2.-Normal seedling (right) and rogue (left) 56 days after sowing. $\times 0{ }^{\circ} 4$. Note the short internodes, smaller leaves and development of the side shoots in the rogue. 

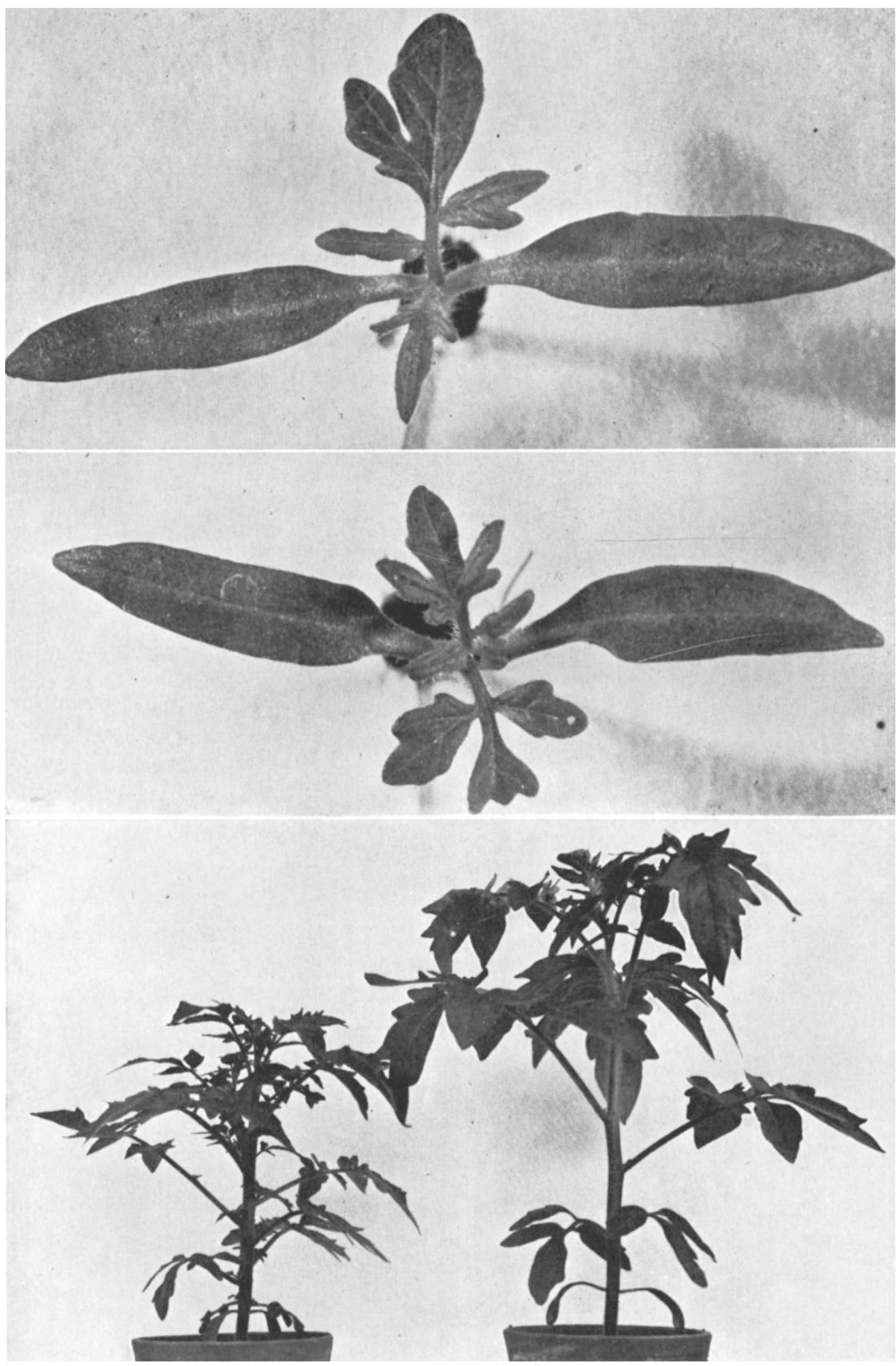
CRANE, M. B. I 939. "Rogues" and segregation in tomatoes. Gard. Chron., 105, 92-93, I I O-I I I.

Darlington, c. D. I 944 . Heredity, development and infection. Nature, Lond., 154, $164-169$.

DARLINGton, C. D. I 949. Genetic particles. Endeavour, 8, 5 1-61.

EPHRUSSI, B., hotTingUer, H., AND CHIMENES, A. M. I949. Action de l'acriflavine sur les levures. I. La mutation " petite colonie". Ann. Inst. Pasteur, 76, 35 I-367. L'hÉrItIER, PH. I 948 . Sensitivity to $\mathrm{CO}_{2}$ in Drosophila. Heredity, 2, 325-348.

magnI, G. E. 1952. Sex-ratio in Drosophila bifasciata. Inst. Lomb. di Sci. et Lett., $85,3-23$.

RICK, C. M. I950. Pollination relations of Lycopersicon esculentum in native and foreign regions. Evolution, 4, I I O-I 22.

SONNEBORN, T. м. 1946. Experimental control of the concentration of cytoplasmic genetic factors in Paramecium. Cold Spr. Harb. Symp. Quant. Biol., II, 236-255.

stanton, W. R. I952. Bolting, a vegetative variation in the potato. Heredity, $6,37-53$. 